\title{
Neural and Behavioral Correlates of Extended Training during Sleep Deprivation in Humans: Evidence for Local, Task-Specific Effects
}

\author{
CGiulio Bernardi, ${ }^{1,2,3}$ Francesca Siclari, ${ }^{1}$ Xiaoqian Yu, ${ }^{1}$ Corinna Zennig, ${ }^{1}$ Michele Bellesi, ${ }^{1}$ Emiliano Ricciardi, ${ }^{2,3}$ \\ [Chiara Cirelli, ${ }^{1}$ Maria Felice Ghilardi, ${ }^{4}$ Pietro Pietrini, ${ }^{2,3}$ and Giulio Tononi ${ }^{1}$ \\ ${ }^{1}$ Department of Psychiatry, University of Wisconsin, Madison, Wisconsin 53519, ${ }^{2}$ Laboratory of Clinical Biochemistry and Molecular Biology, and ${ }^{3}$ Clinical \\ Psychology Branch, University of Pisa, AOUP Santa Chiara, 56126 Pisa, Italy, and ${ }^{4}$ Department of Physiology and Pharmacology, City University of New \\ York Medical School, New York, New York 10017
}

Recent work has demonstrated that behavioral manipulations targeting specific cortical areas during prolonged wakefulness lead to a region-specific homeostatic increase in theta activity $(5-9 \mathrm{~Hz})$, suggesting that theta waves could represent transient neuronal OFF periods (local sleep). In awake rats, the occurrence of an OFF period in a brain area relevant for behavior results in performance errors. Here we investigated the potential relationship between local sleep events and negative behavioral outcomes in humans.

Volunteers participated in two prolonged wakefulness experiments $(24 \mathrm{~h})$, each including $12 \mathrm{~h}$ of practice with either a driving simulation (DS) game or a battery of tasks based on executive functions (EFs). Multiple high-density EEG recordings were obtained during each experiment, both in quiet rest conditions and during execution of two behavioral tests, a response inhibition test and a motor test, aimed at assessing changes in impulse control and visuomotor performance, respectively. In addition, fMRI examinations obtained at $12 \mathrm{~h}$ intervals were used to investigate changes in inter-regional connectivity.

The EF experiment was associated with a reduced efficiency in impulse control, whereas DS led to a relative impairment in visuomotor control. A specific spatial and temporal correlation was observed between EEG theta waves occurring in task-related areas and deterioration of behavioral performance. The fMRI connectivity analysis indicated that performance impairment might partially depend on a breakdown in connectivity determined by a "network overload."

Present results demonstrate the existence of an association between theta waves during wakefulness and performance errors and may contribute explaining behavioral impairments under conditions of sleep deprivation/restriction.

Key words: fMRI; hd-EEG; impulse control; local sleep; performance; theta waves

\section{Introduction}

Sleep is essential to maintain brain operative efficiency, as shown by the well known consequences of its deprivation (difficulty concentrating, emotional instability, etc.) that may lead to car accidents, medical errors, and antisocial behaviors (Alhola and

Received Nov. 5, 2014; revised Jan. 4, 2015; accepted Jan. 26, 2015

Author contributions: G.B., C.C., M.F.G., P.P., and G.T. designed research; G.B., F.S., X.Y., C.Z., M.B., and E.R. performed research; G.B. analyzed data; G.B., F.S., C.C., M.F.G., P.P., and G.T. wrote the paper.

This work was supported by NIH Grant R01MH099231 to C.C. and G.T., McDonnell Foundation (M.F.G. and G.T.), Swiss National Foundation and the Swiss Foundation for Medical-Biological Grants (Grants 139778 and 145763 to F.S.), and the Fondazione Cassa di Risparmio di Lucca (Lucca, Italy). We thank Juan Benzo, Luca Cecchetti, Ching-Sui Hung, Jeffrey Guokas, and Brady Riedner, for help with data collection, technical assistance, and critical discussions, and the ETT s.r.l. (Genova, Italy) for providing the software used for the motor task.

G. Tononi consults for Philips Respironics and is involved in a research study in humans supported by Philips Respironics. This study is not related to the work presented in the current paper. The remaining authors declare no competing financial interests.

Correspondence should be addressed to either of the following: Dr Pietro Pietrini, Professor of Clinical Biochemistry and Molecular Biology, Director, Clinical Psychology Branch, Azienda Ospedaliero Universitaria Pisana, University of Pisa Medical School, Via Roma, 67, 56126 Pisa, Italy, E-mail: pietro.pietrini@med.unipi.it; or Giulio Tononi, MD PhD, Department of Psychiatry, University of Wisconsin-Madison, 6001 Research Park Boulevard, Madison, Wisconsin 53519. E-mail: gtononi@wisc.edu.

DOI:10.1523/JNEUROSCI.4567-14.2015

Copyright $\odot 2015$ the authors $\quad 0270-6474 / 15 / 354487-14 \$ 15.00 / 0$
Polo-Kantola, 2007; Cirelli and Tononi, 2008; Kamphuis et al., 2012). Recent work suggests that sleep and wake, in addition to be controlled at a global level, are also locally regulated, and in either condition "islands" of regional wake and sleep can in fact coexist (Rector et al., 2005; Nobili et al., 2011; Vyazovskiy et al., 2011; Hung et al., 2013). Specifically, in rats forced to stay awake small groups of cortical neurons can show brief periods of neuronal silence (OFF periods) associated with the appearance of slow/ theta waves in the local electroencephalographic (EEG) signal (Vyazovskiy et al., 2011). When local OFF periods happen in areas relevant for behavior, i.e., motor cortex during a reaching task, they lead to performance errors, despite the fact that rats are active and their scalp EEG is typical of wakefulness.

Consistent with these results, in humans, extended practice in a language task or a visuomotor task can lead to a local, taskspecific homeostatic increase in the theta power density of the wake EEG (5-9 Hz), associated with increased slow-wave activity (0.5-4 Hz) over the same brain areas during subsequent sleep (Hung et al., 2013). However, it remains unknown whether the occurrence of local theta waves in the wake EEG can significantly affect brain cognitive processing and lead to performance errors 
in specific tasks. Establishing a direct connection between the two phenomena could help elucidating the mechanisms leading to performance failures during acute sleep deprivation or chronic sleep restriction, when individuals may appear fully awake based on their general behavior and scalp EEG, but some brain areas may be turning OFF at unpredictable times, with potential negative effects on cognitive performance, as well as on behavioral control.

To explore these issues, we investigated whether errors in behavioral tests show a temporal association with the occurrence of theta waves over task-related areas. In two separate prolonged waking experiments ( $24 \mathrm{~h}$, no sleep), subjects repeatedly practiced one of two cognitive tasks challenging partially distinct neural circuits: a series of "executive function" (EF) tasks, predominantly involving frontal areas implicated in impulse control (Garavan et al., 2002), and a driving simulation (DS) task prevalently engaging posterior regions implicated in visuospatial processing and visuomotor coordination (Walter et al., 2001). During each experiment, highdensity (hd)-EEG was recorded in a resting condition and during the execution of two computerized tests, a response inhibition test and a visuomotor test, selected to track variations in impulse control and visuomotor coordination, respectively. Moreover, we detected theta waves occurring during each recording to determine the potential temporal and spatial relationship between their occurrence and behavioral errors. Finally, resting state fMRI examinations obtained at $12 \mathrm{~h}$ intervals were used to investigate whether variations in the occurrence of local theta waves can be associated to changes in regional connectivity during the two experiments.

\section{Materials and Methods}

\section{Participants}

A total of 16 healthy participants (age $=21-34$ years, mean \pm SD $=$ $24.0 \pm 3.4$ years, 8 females; 13 right-handed) were recruited from the University of Wisconsin-Madison campus. All participants slept an average of 7-8 h/night, had consistent bed/rise times, no daytime nap habit, no excessive daytime sleepiness (total scores in the Epworth Sleepiness Scale $\leq 10$ ) and no history of sleep, medical, or psychiatric disorders as assessed by a clinical interview and by one $8 \mathrm{~h}$ night sleep recording with hd-EEG (baseline sleep night). The study was approved by the local IRB. Each participant signed an IRB approved informed consent form before enrollment into the study. One of the volunteers (male, lefthanded) withdrew from the study after the first experiment and was excluded from all the analyses.

\section{Experimental design}

Participants completed two prolonged wakefulness experiments $(24 \mathrm{~h})$ separated by at least 2 weeks, in a random and counterbalanced order. Each experiment included six $2 \mathrm{~h}$ sessions of either an EF battery, including visual tasks based on impulse control, decision making, and conflict resolution (Table 1), or a mouse-controlled DS computer game (Fig. 1). $\mathrm{EF}$ and DS were selected to engage as much as possible distinct cognitive functions and brain cortical networks, although partial overlap was inevitable. On one hand, EFs are known to be associated with the recruitment of a predominantly frontal network (Garavan et al., 1999, 2002; Hofmann et al., 2012), including the medial prefrontal cortex (mPFC) and the presupplementary motor cortex (pre-SMA), the bilateral dorsolateral prefrontal cortex (DLPFC), and the right inferior parietal lobule (IPL). On the other hand, driving simulation, which is based on visuospatial abilities and visuomotor coordination, prevalently activates occipitoparietal regions bilaterally (Walter et al., 2001; Jeong et al., 2006; Hung et al., 2013). To minimize the use of executive functions, such as decision-making and impulse control, for the DS task, the break function was deactivated and subjects were asked to focus on improving their control of the car.

To enhance active participation and engagement, subjects were tested in pairs. Alcohol and caffeine-containing beverages were prohibited

\section{Table 1. Tasks included in the EF battery}

\begin{tabular}{|c|c|c|}
\hline Task & Description & References \\
\hline Stroop task & $\begin{array}{l}\text { Subjects were asked to complete a full } \\
\text { session ( } 6 \text { blocks) of the Psychol- } \\
\text { ogy Experiment Building Language } \\
\text { version of the Stroop task ( } \sim 20 \\
\text { min) }\end{array}$ & $\begin{array}{l}\text { Stroop, 1992; DeWall } \\
\text { et al., 2007; Mueller, } \\
2009\end{array}$ \\
\hline Visual attention task & $\begin{array}{l}\text { Subjects were instructed to concen- } \\
\text { trate their attention on a (mute) } \\
\text { speaker, while ignoring words } \\
\text { presented in either the bottom left } \\
\text { or right corner of the monitor ( } 2 \\
\text { trials, } 9 \text { min }+1 \text { min interval } \\
\text { each) }\end{array}$ & $\begin{array}{l}\text { DeWall et al., 2007; } \\
\text { Gailliot et al., 2007; } \\
\text { Fischer et al., } 2008\end{array}$ \\
\hline $\begin{array}{l}\text { Emotion suppression } \\
\text { task }\end{array}$ & $\begin{array}{l}\text { Subjects were instructed to maintain a } \\
\text { neutral facial expression (in partic- } \\
\text { ular not to yawn or laugh) while } \\
\text { watching a boring ( } 9 \text { min }+1 \text { min } \\
\text { interval) or a funny ( } 9 \text { min }+1 \\
\text { min interval) short video including } \\
\text { clips depicting people yawing or a } \\
\text { collection of funny situations, } \\
\text { respectively }\end{array}$ & $\begin{array}{l}\text { Baumeister et al., 1998; } \\
\text { Muraven et al., } \\
\text { 1998; Vohs and } \\
\text { Heatherton, 2000; } \\
\text { Muraven and Sles- } \\
\text { sareva, 2003; Stucke } \\
\text { and Baumeister, } \\
\text { 2006; Fischer et al., } \\
2008\end{array}$ \\
\hline $\begin{array}{l}\text { Response conflict } \\
\text { task }\end{array}$ & $\begin{array}{l}\text { Subjects were presented with } 180 \\
\text { simple short questions (e.g., "what } \\
\text { is the color of the sun?") and two } \\
\text { possible answers (e.g., "yellow or } \\
\text { blue"). With a } 300 \text { ms delay, a } \\
\text { green or a red sign appeared below } \\
\text { the question, indicating whether } \\
\text { the subject had to give the correct } \\
\text { or the wrong response, respec- } \\
\text { tively. Subjects were required to } \\
\text { respond as fast and as accurately as } \\
\text { possible ( } \sim 20 \mathrm{~min})\end{array}$ & $\begin{array}{l}\text { Modified from Nuñez } \\
\text { et al., } 2005\end{array}$ \\
\hline Blackjack task & $\begin{array}{l}\text { Subjects were required to play a } \\
\text { Blackjack game, which is known to } \\
\text { involve risk evaluation, decision- } \\
\text { making and gambling-related } \\
\text { impulse control ( } \sim 25 \text { min) }\end{array}$ & $\begin{array}{l}\text { Hewig et al., 2007; } \\
\text { Vohs et al., 2008; } \\
\text { Hewig et al., 2009 }\end{array}$ \\
\hline
\end{tabular}

starting the night before and throughout each experiment. Participants were asked to maintain their regular sleep-wake schedule for at least 1 week before each experiment. Compliance was verified by wrist-worn actimeters (Actiwatch 64, MiniMitter) and with sleep diaries. The night before the experiment, participants were asked to go to bed at their usual bedtime, to wake up at $\sim 07: 00$ and to arrive at the lab at 08:00. As shown in Figure 1, each experiment began with an MRI recording (see below), repeated at 20:00, after $12 \mathrm{~h}$ spent awake, and the following day at 8:00, after $24 \mathrm{~h}$ spent awake, and at 20:00, after recovery sleep (RS). After the first MRI, subjects completed a $1 \mathrm{~h}$ test-block that served as baseline. Then, the test-block was repeated after each $2 \mathrm{~h}$ task session in the first $24 \mathrm{~h}$ and also after the recovery sleep the following day. A $\sim 45 \mathrm{~min}$ interval between the awakening and the beginning of the last test-block was scheduled to minimize the influence of sleep inertia on cognitive performance (Jewett et al., 1999). It should be noted that recovery sleep occurred in the morning in all subjects. Although the effects of recovery sleep were not the main focus of the present work, the circadian phase can influence various aspects of sleep, including number of arousals and/or amount of time spent in REM sleep. On the other hand, previous findings including some from our laboratory (Hung et al., 2013) indicate that sleep in the morning can be sufficient to revert homeostatic changes produced by prior sustained wakefulness, and thus represents a valid approach for the study of these effects.

Based on a pilot study, standardized quantities of food were provided at 14:00 and 21:00 of the first day, and at $\sim 2: 00$ and 18:00 (after recovery 
Tasks

$\begin{gathered}\text { Driving Simulation (DS) } \\ \text { Visuo-Motor Network }\end{gathered}$
Executive Function Battery (EF)
Prefrontal Network

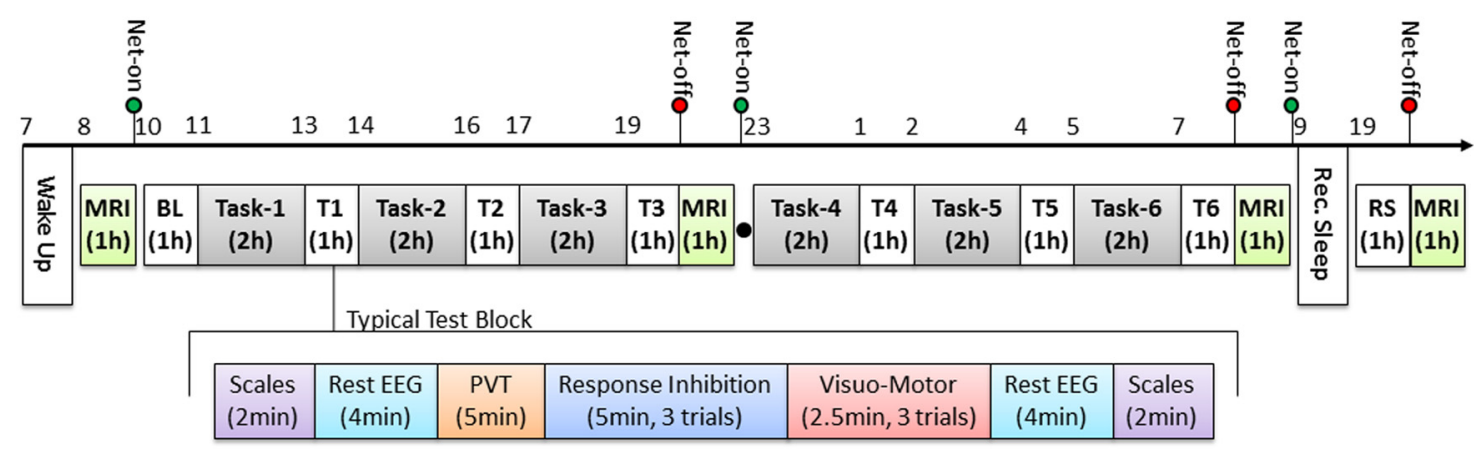

Figure 1. Experimental design. In each experiment participants woke up at $\sim 07: 00$ and underwent a BL at 10:00, followed by six $2 \mathrm{~h}$ tasks (EF or DS) interleaved by $\sim 1 \mathrm{~h}$ EEG recording block (T1-T6, total wake time: $24 \mathrm{~h}$ ). A final test-block was scheduled $\sim 45 \mathrm{~min}$ after participants woke up from $\sim 8 \mathrm{~h}$ of RS. During each experiment, MRI scans were obtained at $8: 00$ of the first day, after 12 and $24 \mathrm{~h}$ of wake, and at 20:00 of the second day (after RS). During each $1 \mathrm{~h}$ test-block EEG activity was recorded while subjects completed a PVT, two 4 min resting conditions (eyes open, eyes (losed), and three trials of a response inhibition test interleaved with three trials of a visuomotor test (participants alternated between the two tests, the order of which was counterbalanced across subjects and experiments). At the beginning and at the end of each test-block subjective sleepiness was evaluated using self-rating questionnaires.

sleep) of the following day. Each test-block included: two 2 min resting state EEG recordings with eyes open and two 2 min recordings with eyes closed (each, $4 \mathrm{~min}$ in total); three trials of two behavioral tests that were used to monitor changes in impulse control and visuomotor performance throughout the DS and EF experiments; a 5 min psychomotor vigilance test (PVT; Dinges and Powell, 1985; Roach et al., 2006; Basner and Dinges, 2011). During PVT (adapted from Hung et al., 2013) subjects were instructed to respond as fast as possible when a millisecond counter appeared on the computer's screen. Following each button press (or after $5 \mathrm{~s}$ if no response was produced) the counter scrolling was stopped and a new counter appeared after a randomly selected interval comprised between 2 and $12 \mathrm{~s}$. At the end of the test-block, subjects had a 10 min break. Before and after each test-block, subjective sleepiness was evaluated with self-rating questionnaires. Two experimenters took turns attending to the participants to prevent them from falling asleep and to ensure adherence to the protocol throughout the entire experiment. During all tasks and EEG recordings, with the exception of the PVT, the experimenters alerted the participants each time signs of drowsiness were detected (closure of eyelids, slow eye movements, eye blinks). To ensure signal quality during EEG recordings, electrode impedance was checked before each test-block and kept $<50 \mathrm{KU} \Omega$.

\section{Behavioral tests}

Response inhibition test. To investigate whether and to which degree prolonged practice with the two experimental tasks differently affected the impulse control performance, during each test-block subjects completed a modified version of the "XY response inhibition test" (Garavan et al., 1999; Roche et al., 2005). During this test, a stream of visual stimuli, consisting of capital letters X or Y, was presented in alternating order at a rate of one per second. Each stimulus remained visible for $600 \mathrm{~ms}$. Subjects were instructed to click the left mouse button for every stimulus that followed a different stimulus (Go), and to withhold their response each time two identical stimuli followed each other (NoGo). Each test trial lasted 5 min and included 300 stimuli, 30 of which represented "lures" requiring withhold. Individual cases in which reaction time exceeded 500 ms were considered as lapses and excluded from further evaluation. Inhibitory efficiency was assessed using two parameters: the number of commission errors (i.e., cases in which the subject responded despite a
NoGo stimulus was presented) and the intraindividual coefficient of variation in reaction time (ICV; Stuss et al., 2003; Chuah et al., 2006) during correct responses (i.e., cases in which the subject correctly pressed the button when a Go stimulus was presented). As previously described (Stuss et al., 2003), the ICV was computed as the SD of each subject's reaction time divided by the mean reaction time across all correct responses. Previous studies demonstrated that the ICV represents an indicator of cognitive performance instability, and that changes in this parameter are strongly correlated with those shown by other measures of self-control and impulsiveness (Chuah et al., 2006). Cases in which participants successfully inhibited their motor response when a NoGo stimulus was presented ("correct withholds") were also identified and stored for specific comparisons detailed below.

Visuomotor test. A validated "reaching test" (Ghilardi et al., 2003; Moisello et al., 2008; Ghilardi et al., 2009) was used to assess changes in visuomotor control through the DS and EF experiments. During this test, volunteers were required to perform straight, out and back movements of a tracker, held with the dominant hand, from a central starting area to one of eight radial targets (distance from center $=5 \mathrm{~cm}$ ). The starting area and target locations were displayed on the computer's screen as $2 \mathrm{~cm}$ diameter circles on a white background. Targets were presented in a pseudorandom order at regular intervals of $1.5 \mathrm{~s}$. Each test trial included 88 movements, and lasted $132 \mathrm{~s}$. Subjects were instructed to move as fast and as accurately as possible. For all statistical analyses, individual movements including clear lapses (reaction time $>500 \mathrm{~ms}$ or movement time $>1000 \mathrm{~ms}$ ), or for which the cursor was directed toward the wrong target (directional error $>22^{\circ}$ ), were excluded from evaluation. Efficiency in visuomotor control was assessed using two parameters: movement time, the time from movement onset to reversal, and linear error, the distance of the reversal point from the center of the target. Importantly, movement time has been shown to be strongly correlated with movement peak velocity and acceleration in case of rapid, ballistic movements, such as those required in this test (Moisello et al., 2011).

Performance evaluation and statistical analyses. The afternoon of the day preceding each prolonged waking experiment, volunteers came to the laboratory for a $1 \mathrm{~h}$ training session. In this occasion, subjects were instructed about the study procedures and completed three trials for each 
of the two behavioral tests, to become familiar with the tests' requirements and to minimize any potential learning effects. As described by Hung et al. (2013), for each subject, the performance level achieved during each test-block of the prolonged waking experiments was expressed as the ratio computed dividing the measured performance parameter by a "common baseline" (cBL) obtained from the average of the performance values obtained during the first test-block (BL) of both DS and EF experiments. Repeated-measures analyses of variance (rmANOVA) were used to test the potential effects of time spent awake ("block"). Moreover, to verify whether the two experimental conditions differentially affected behavioral performance, we compared the parameters of interest obtained in two specific test-blocks, corresponding to $12 \mathrm{~h}$ spent awake (T3, "normal waking period"), and $24 \mathrm{~h}$ spent awake (T6, "prolonged waking”), via paired $t$ tests.

\section{Resting eyes open EEG data}

Hd-EEG was recorded with a 256-channel EEG from EGI (Electrical Geodesics) using a sampling frequency of $500 \mathrm{~Hz}$. For each test session, the $4 \mathrm{~min}$ of spontaneous eyes-open EEG data were first-order high-pass filtered (Kaiser type FIR, $0.5 \mathrm{~Hz}$ ) and low-pass filtered $(58 \mathrm{~Hz}$ ). Each recording was divided in $4 \mathrm{~s}$ epochs and visually inspected to identify channels and epochs containing artifacts. Rejected channels were interpolated using spherical splines (NetStation, Electrical Geodesic). Then, independent component analysis was performed in EEGLAB (Delorme and Makeig, 2004) to identify and remove ocular, muscular, and electrocardiographic artifacts. After excluding electrodes located on the neck/ face region, the signal of each channel was re-referenced to the average of the remaining 185 channels. Based on previous evidence indicating that in humans, as in rats, local sleep events may be associated with EEG waves in the theta frequency range (Hung et al., 2013), a spectral power analysis in a low-frequency range $(0-12 \mathrm{~Hz})$ was performed. Specifically, for each EEG derivation, power spectral density estimates were computed with the Welch's method ( $p$ welch function, MATLAB signal processing toolbox) in $4 \mathrm{~s}$ data segments using Hamming windows (8 sections, $50 \%$ overlap, $0.25 \mathrm{~Hz}$ bin resolution). Data segments were then averaged and adjacent frequency bins were collapsed to obtain $1 \mathrm{~Hz}$ bins. Finally, the resulting power spectral densities were averaged across all electrodes. The same procedure was applied to all recording sessions for each subject, and group results were plotted (see Fig. 3) to determine the frequency range associated with the largest increase in power spectral density during sleep deprivation.

A theta-wave automated detection algorithm was applied as previously described (Hung et al., 2013). Specifically, the preprocessed EEG signal from each electrode was re-referenced to the average of the two mastoids and high-pass filtered at $2.5 \mathrm{~Hz}$. Then, individual half-waves were detected through the identification of negative signal deflections between two consecutive zero crossings (Riedner et al., 2007; Hung et al., 2013; Siclari et al., 2014). Based on the power spectral density analysis results (see Results and Fig. 3), and on our previous report (Hung et al., 2013), we focused the detection on half-waves in the 5-9 Hz frequency range. An amplitude threshold set at the top $20 \%$ amplitude of all detections was applied to each channel and recording session to avoid potential confounding effects due to spurious low amplitude deflections of the signal. For each electrode, we calculated the theta wave density as the number of theta waves per minute. Then, we computed the ratio between the obtained density value and the mean theta wave density of the common baseline calculated across the two conditions. Finally, density values were normalized by applying a Z-score transformation across channels.

To determine whether specific changes in theta activity were associated with an effect on performance indices, we evaluated the acrosssubjects correlation between relative interexperiment (EF vs DS) differences in theta wave density and behavioral performance. Specifically, for each participant, we first calculated the difference between the mean performance values achieved during EF and DS experiments in the response inhibition and in the visuomotor test. Then, the same was done for the theta wave density at each electrode, and the Pearson's correlation coefficient was calculated between the obtained values and the relative performance changes at the group level. We focused on positive correlations (proportional to the association between theta wave density and
Table 2. Results of the one-way rmANOVAs testing the effect of block on subjective and objective indices of sleepiness

\begin{tabular}{|c|c|c|c|c|}
\hline \multirow[b]{2}{*}{ Variable } & \multicolumn{4}{|c|}{ One-way rmANOVAs } \\
\hline & DS & & $\mathrm{EF}$ & \\
\hline $\begin{array}{l}\text { Stanford sleepiness } \\
\text { scale }\end{array}$ & $F_{(7,98)}=31.2$ & $p=3 \times 10^{-22}$ & $F_{(7,98)}=24.1$ & $p=9 \times 10^{-19}$ \\
\hline Alertness & $F_{(7,98)}=23.2$ & $p=3 \times 10^{-18}$ & $F_{(7,98)}=31.6$ & $p=2 \times 10^{-22}$ \\
\hline Mood & $F_{(7,98)}=13.0$ & $p=1 \times 10^{-11}$ & $F_{(7,98)}=12.5$ & $p=2 \times 10^{-1}$ \\
\hline Sleepiness & $F_{(7,98)}=11.6$ & $p=1 \times 10^{-10}$ & $F_{(7,98)}=8.8$ & $p=2 \times 10^{-8}$ \\
\hline PVT & $F_{(7,98)}=10.4$ & $p=1 \times 10^{-9}$ & $F_{(7,98)}^{(7,70)}=15.6$ & $p=2 \times 10^{-13}$ \\
\hline EEG theta power & $F_{(7,84)}=5.5$ & $p=3 \times 10^{-5}$ & $F_{(7,84)}=5.5$ & $p=3 \times 10^{-5}$ \\
\hline
\end{tabular}

performance degradation) because due to this approach, regions for which theta wave density was higher in one experiment (e.g., EF) acquired positive values, whereas regions in which density was higher in the other experiment (e.g., DS) acquired negative values. Thus, negative correlations were expected to just "mirror" positive correlations and were excluded from evaluation.

This analysis and those described in the following sections were performed on data collected during test-block T3 $(\sim 12 \mathrm{~h}$ of waking). This particular block was selected for different reasons. First, both our previous study (Hung et al., 2013) and preliminary evaluations of the present dataset (see Results) showed that this time of the day, roughly corresponding to the "forbidden zone" for sleep (i.e., the few hours before the major sleep phase, characterized by the strongest drive to wakefulness; Lavie, 1986), is characterized by a temporary decrease in global theta activity, which can be expected both to favor the emergence of local, experience-dependent differences, and to minimize potential confounding effects determined by the nonspecific increase in theta wave incidence on cognition and behavior. Moreover, the availability of fMRI data obtained immediately after the T3 block (due to the scheduled $12 \mathrm{~h}$ interval between sessions) allowed both fMRI and EEG analyses to be focused on a well defined, consistent time-window. Thirteen subjects were included in this evaluation (EEG recordings from the EF experiment of two subjects were lost due to technical problems).

\section{Temporal association between theta waves and errors in \\ behavioral tests}

To investigate whether theta waves may represent a potential cause of behavioral impairment, the same theta wave detection algorithm described above was applied to each of the EEG recordings obtained during execution of the tests.

Response inhibition test. For each electrode, we identified theta waves that showed a maximum negative peak in a window of $500 \mathrm{~ms}$ after stimulus presentation. Then, the percentage of commission errors (i.e., impulse control failures), correct withholds (i.e., impulse control successes), and correct responses associated with the presence of a theta wave was calculated. We also computed the probability of association between theta waves and the subject's motor response by identifying waves that peaked $150 \mathrm{~ms}$ before or after button press in correct responses (Go) and commission errors (NoGo). In cases in which reaction time was shorter than $150 \mathrm{~ms}$, the time window of interest only included the time between stimulus presentation and subject's response. An rmANOVA was used to test the hypothesis of a specific spatial and temporal association between theta waves and commission errors as compared with conditions not associated with an impulse control failure, i.e., correct withholds. Areas that showed a significant outcome effect were used as regions-of-interest (ROIs) for subsequent post hoc comparisons.

Visuomotor test. Whereas in the response inhibition test errors and correct responses were mutually exclusive and clearly distinguishable from each other, in the visuomotor test performance was expressed by continuous variables for which a clear cutoff to define "errors" was not easily identifiable, due to intersubject and intertrial variability. Thus, an ROI-based approach was used. Specifically, for both movement time and linear error, areas showing a significant correlation between theta activity at rest and performance (eyes-open condition) were used as ROIs for the detection of theta waves peaking in the time-window comprised between 

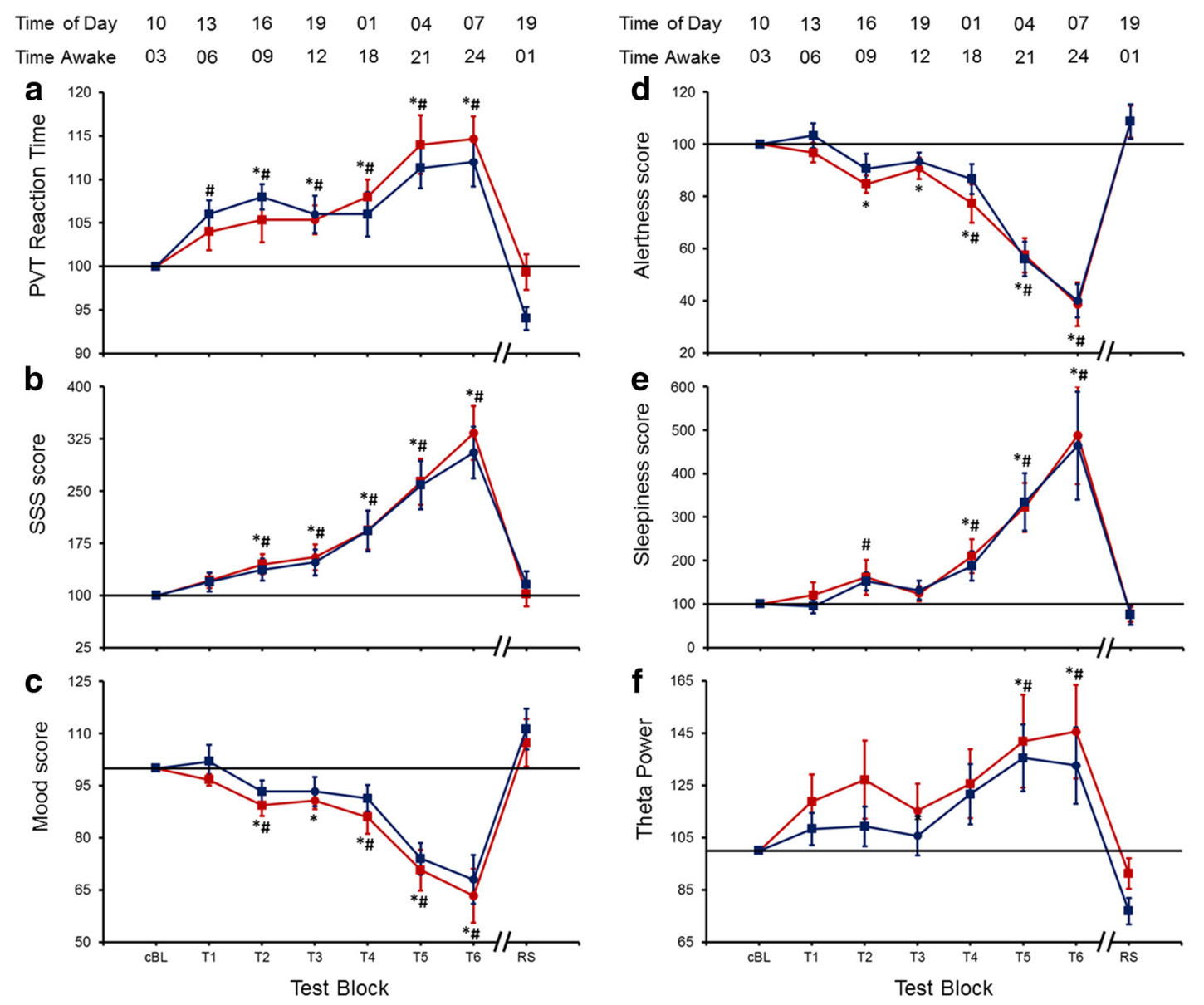

$\square$ Driving Simulation * Significant difference compared to cBL

$\square$ Executive Function \# Significant difference compared to cBL

Figure 2. Changes in objective and subjective measures of alertness: (a) PVT mean reaction time, (b) Stanford Sleepiness Scale (SSS) score, (c) subjective mood, (d) subjective alertness, (e) subjective sleepiness, and $(\boldsymbol{f})$ global EEG theta power. Each trace depicts mean \pm SE (15 subjects, 13 for theta power) of each block expressed relative to the $c B L(=100)$, defined as the average between baseline values during DS and EF experiments. One-way rmANOVAs revealed the existence of significant block effects in both experiments for all parameters (Table 2). Paired $t$ tests were used to compare each testing session with cBL. * and \# mark significant changes from $c B L(p<0.05)$ in DS and EF, respectively.

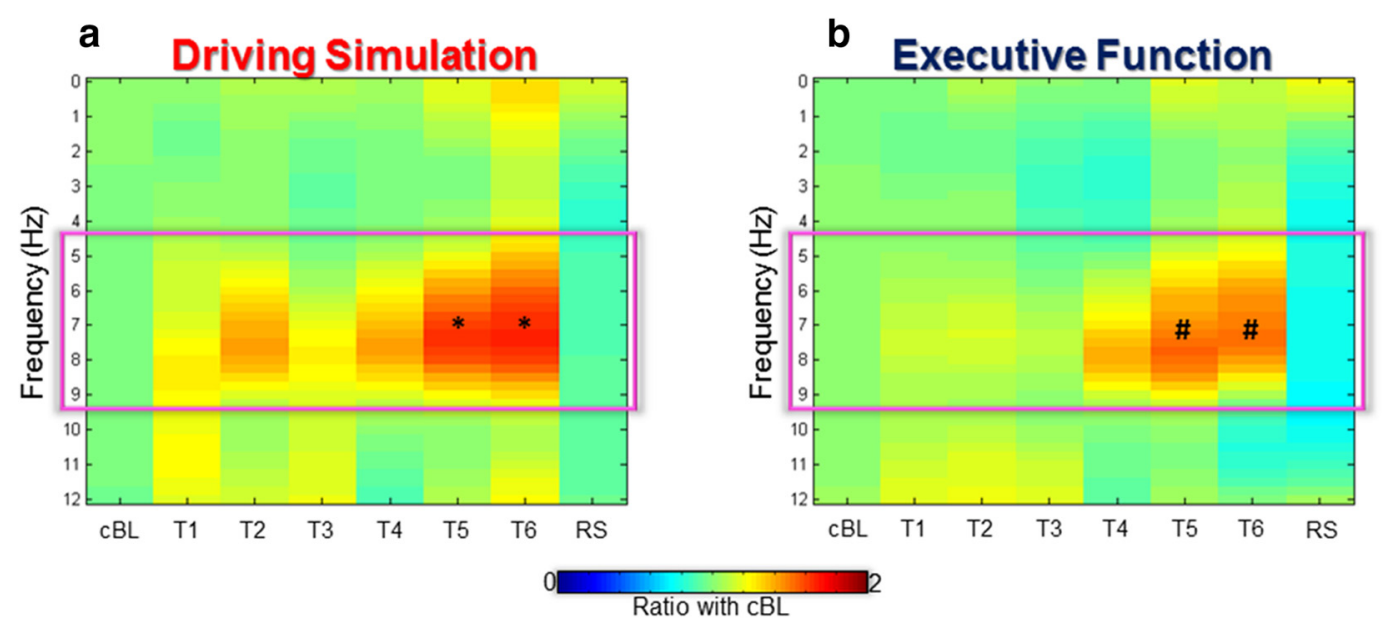

Figure 3. Effects of prolonged wake on EEG power spectral density during the DS $(\boldsymbol{a})$ and $\mathrm{EF}(\boldsymbol{b})$ experiments and after $\mathrm{RS}$. Power density values in the range 0 - $12 \mathrm{~Hz}$ were calculated with a bin resolution of $1 \mathrm{~Hz}$ and averaged across channels. For each frequency bin we calculated the ratio with a CBL defined as the average between baseline values during DS and EF experiments. The one-way rmANOVA showed a significantblock effect on global EEG theta power during both experiments (Table 2). On average, the global increase in theta activity was relatively stronger during the DS (15 subjects) than during the EF (13 subjects) experiment. Paired $t$ tests comparing changes in theta power $(5-9 \mathrm{~Hz})$ with the common baseline indicated that the global increase became statistically significant during session T5 $(\sim 21 \mathrm{~h} s p e n t$ awake) in both DS ( $p=$ $0.034)$ and $\mathrm{EF}(p=0.015)$. After recovery sleep, a decrease in power density was observed in all frequency bins. * and \# marksignificant changes from $\mathrm{BL}(p<0.05)$ in DS and EF, respectively. 
stimulus presentation and movement onset. This time-window was selected based on the assumption that theta waves occurring during movement preparation would interfere with visuomotor coordination. Then, for each experimental condition (DS, EF) movements characterized by the presence or absence of a theta wave were directly compared with respect to the performance parameter of interest (paired $t$ tests).

Cluster-threshold in EEG analyses. To enhance the power of the statistical tests for all EEG analyses and minimize potential false positive results we applied a minimum cluster-size threshold determined using a Monte-Carlo simulation (Forman et al., 1995) including the following steps (5000 repetitions): random activity generation (a value comprised between 0 and 1 was assigned to each channel), individual channel probability thresholding $(\alpha=0.05)$, calculation, and storage of the maximum size of the surviving "activity" clusters. The obtained cluster-size frequency table was then used to determine a minimum cluster size threshold, corresponding to the $95^{\text {th }}$ percentile of the whole distribution (i.e., 3 electrodes).

\section{Functional connectivity analysis of}

\section{MRI data}

An MRI-based connectivity analysis was used to determine whether theta waves occurring in wake, potentially reflecting OFF periods functionally similar to those characterizing slow-wave sleep (Massimini et al., 2005), are associated with a temporary reduction in inter-regional coupling. We evaluated both the global effects on activity synchronicity using voxelwise measures of whole-brain correlation (Tomasi and Volkow, 2010) and signal variability (Garrett et al., 2010, 2011), as well as potential local effects on task-related networks using a ROI-based approach. To this aim, during each MRI session (3T scanner, Discovery MR750, GE Medical Systems) subjects underwent a $5 \mathrm{~min}$ eyes-closed EPI resting-state scan (repetition time: $2000 \mathrm{~ms}$, echo time: $25 \mathrm{~ms}$, flip angle: 60, voxel size: $3.5 \times 3.5 \times 1.8 \mathrm{~mm}$, plane: $128 \times$ 128 , number of slices: 40 , total number of volumes: 150) and a high-resolution FSPGR T1 anatomical scan (repetition time: $8.2 \mathrm{~ms}$, echo time: $3.2 \mathrm{~ms}$, inversion time: $450 \mathrm{~ms}$, flip angle: 12 , voxel size: $1 \times 1 \times 1 \mathrm{~mm}$, plane: $256 \times 256$, number of slices: 156). Because of technical problems, one subject (male, right handed) did not undergo MRI scans and was excluded from the present analysis $(n=14)$.

The AFNI software package was used to preprocess, analyze and view functional and structural imaging data (Cox, 1996, 2012). All volumes obtained during the resting condition were concatenated and coregistered, temporally aligned, and spatially smoothed (FWHM $=6 \mathrm{~mm})$. Individual run data were normalized by calculating the mean intensity value for each voxel during resting baseline time-points, and by dividing the value within each voxel by this averaged baseline to estimate the percentage signal change at each time point. Individual functional images were trans-

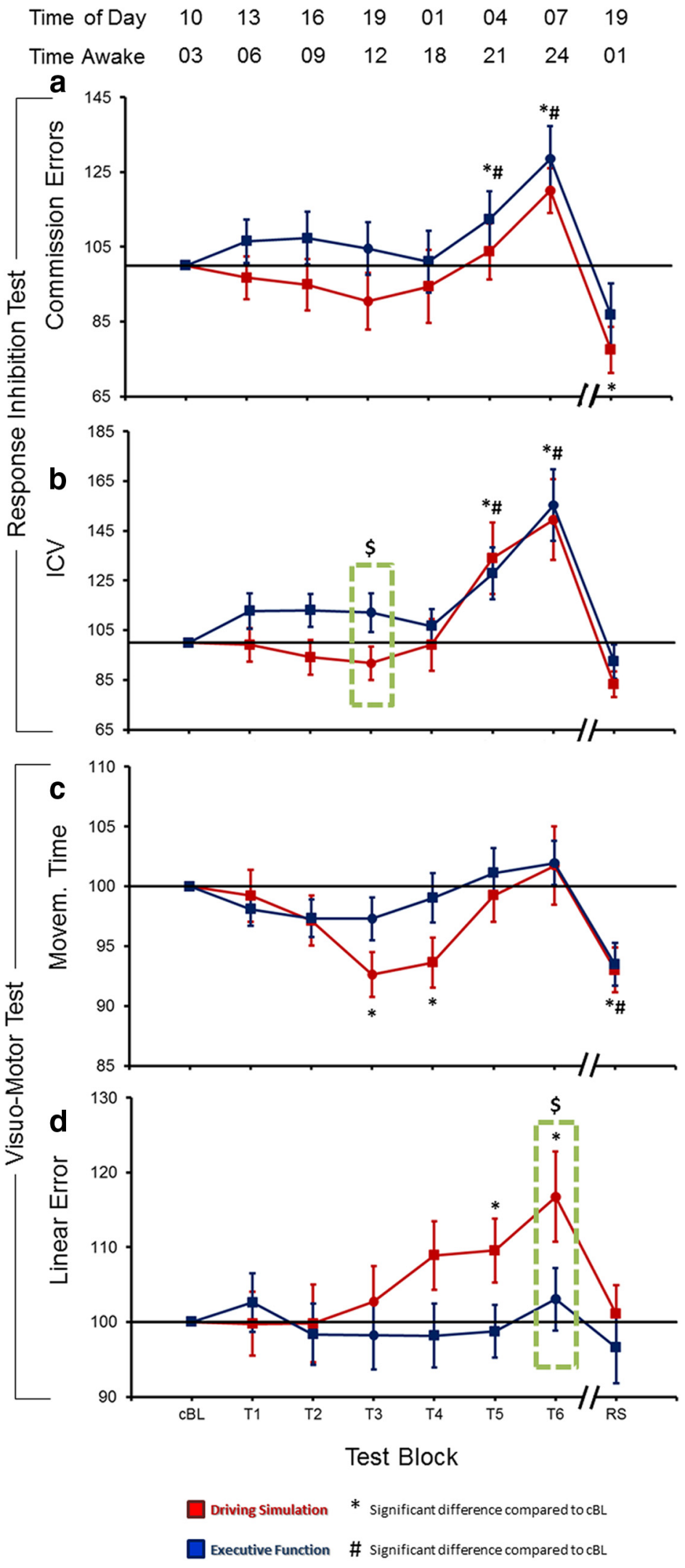

Figure 4. Changes in behavioral performance during prolonged wakefulness: (a) number of commission errors and (b) ICV for the response inhibition test; (c) movement time (time from movement onset to reversal) and (d) linear error (shortest distance of the reversal point from the center of the target) for the visuomotor test. Each trace depicts mean \pm SE (15 subjects) of each block expressed relative to $\mathrm{CBL}(=100)$. One-way mANOVAs testing the effects of time spent awake confirmed the existence of significant block effects for all parameters and for both experimental conditions (DS, EF), with the exception of linear error during $\operatorname{EF}(T a b l e s 3,4) .{ }^{*}$ and \# mark significant changes from $\mathrm{BL}$ ( $p<$ $0.05)$ in DS and EF, respectively. \$and dashed green boxes indicate significant differences between experimental conditions $(p<0.05)$. 
Table 3. Results of the one-way rmANOVAs testing the effect of session on behavioral performance during the response inhibition tests

\begin{tabular}{lllll}
\hline & \multicolumn{2}{l}{ One-way rmANOVAs } \\
\cline { 2 - 5 } Response inhibition & \multicolumn{2}{l}{ Driving simulation (DS) } & \multicolumn{2}{l}{ Executive function (DS) } \\
\hline ICV & $F_{(7,98)}=9.9$ & $p=3 \times 10^{-9}$ & $F_{(7,98)}=8.0$ & $p=1 \times 10^{-7}$ \\
Commission errors & $F_{(7,98)}=5.7$ & $p=2 \times 10^{-5}$ & $F_{(7,98)}=5.2$ & $p=4 \times 10^{-5}$ \\
\hline
\end{tabular}

Table 4. Results of the one-way rmANOVAs testing the effect of session on behavioral performance during the visuomotor tests

\begin{tabular}{lllll}
\hline & \multicolumn{2}{l}{ One-way rmANOVAs } & \\
\cline { 2 - 5 } Visuomotor control & Driving simulation (EF) & \multicolumn{2}{l}{ Executive function (EF) } \\
\hline Linear error & $F_{(7,98)}=4.3$ & $p=4 \times 10^{-4}$ & $F_{(7,98)}=0.8$ & $p=$ n.s. \\
Movement time & $F_{(7,98)}=4.5$ & $p=2 \times 10^{-4}$ & $F_{(7,98)}=4.6$ & $p=2 \times 10^{-4}$ \\
\hline
\end{tabular}

formed into the Talairach and Tournoux Atlas (Talairach and Tournoux, 1988) coordinate system, and resampled into $2 \mathrm{~mm}^{3}$ voxels for group analyses. To minimize the contribution of noise caused by movements and physiological artifacts, voxel time-series were further adjusted by regressing out motion correction parameters, white matter (WM) and CSF time-series, and a polynomial function modeling the BOLD drifting effect (Lund et al., 2006). A $0.01 \mathrm{~Hz}$ high-pass filter was also applied. WM and CSF time courses were extracted from two 1-voxel-radius ROIs, respectively, located in corpus callosum and ventricles of the "common template" obtained by merging spatially normalized anatomical images of all subjects (Leo et al., 2012).

With regard to the whole-brain analysis, we calculated two parameters for each voxel, the mean global correlation, computed as the average of all positive correlations with other voxels of the brain (within an atlasbased cortical mask; Eickhoff et al., 2005), and the temporal signal variability, defined using the mean square successive difference (von Neumann et al., 1941). Importantly, this latter measure is related to information integration and functional connectivity (Garrett et al., 2011; Leo et al., 2012; Bernardi et al., 2013; Ricciardi et al., 2013). Moreover, based on results obtained in the behavioral and EEG analyses (see Results), we investigated potential changes in brain functional connectivity within the networks of two specific regions of interest (6-mm-radius spheres): anterior cingulate cortex $(x=-2, y=-18, z=39$; Garavan et al., 2002) and left primary motor area $(x=-25, y=-15, z=50$; Bernardi et al., 2014). These two regions are involved in impulse control (Garavan et al., 2002) and in driving behavior, respectively (Bernardi et al., 2014). For each subject and experiment, the Pearson's correlation coefficient was computed between the averaged signal time course of the seed ROIs and the time course of all the other voxels of the brain. Obtained correlation coefficients were converted into Z-scores using Fisher's transformation (Zar, 1996).

rmANOVAs including experiment (DS, EF) and scan session (baseline, 12 and $24 \mathrm{~h}$ of waking) were used to identify regions characterized by significant changes in parameters of interest as a function of prior waking time and potential experiment $\mathrm{X}$ session interactions. A cluster-based correction (Forman et al., 1995) was applied ( $p<0.01$, minimum cluster size of 107 voxels) to achieve a corrected significance threshold of $p<0.05$.

\section{Results}

Effects of prolonged wake on sleepiness, vigilance, and global wake EEG power

The results of rmANOVAs assessing the effect of time spent awake (block) on all measures of sleepiness are reported in Table 2. Briefly, subjective and objective measures of sleepiness were modulated by prolonged waking in a similar manner during the DS and the EF experiments, indicating that these conditions were characterized by similar global homeostatic changes in sleep need and by a similar modulation of the general vigilance level (Fig. 2). Specifically, subjective measures of sleepiness and PVT reaction time significantly increased during prolonged waking, reaching a peak at T6 (24 h of wake), and dropped after the recovery sleep. Compared with the baseline values, these increases showed a first peak at $\sim 9$ h of waking (T2), followed by a temporary relative decrease or stabilization at $\sim 12 \mathrm{~h}$ (T3), and by a subsequent steep increase (Fig. 2).

Analysis of the global EEG spectral power showed that in both experiments, the frequencies ranging from 5 to $9 \mathrm{~Hz}$ (theta power) significantly increased during the period spent awake, consistent with previous work (Hung et al., 2013; Fig. 3). On average, the increase of power ratio was significantly greater in the DS experiment. However, in both experimental conditions, the changes in global EEG theta power showed a time course similar to the one described for the subjective and objective measures of sleepiness, thus confirming the previously described correlation between these parameters and theta activity during sleep deprivation (Hung et al., 2013).

\section{Effects of prolonged wake and behavioral manipulations on performance}

Response inhibition test

During both experiments the number of commission errors in the response inhibition test increased during the wake period, with a peak at T6 $(24 \mathrm{~h})$, and decreased below baseline level after recovery sleep (Fig. 4a; Table 3 ). Similar trends were noted for the ICV in reaction time (Fig. $4 b$; Table 3 ). Changes in this parameter were highly correlated with those in the number of commission errors (DS: $r=0.91, p=0.0018$; EF: $r=0.97, p=0.0001$ ). Importantly, we found a significant difference between the two experimental conditions during the T3 test-block $(\sim 12 \mathrm{~h}$ of wake), with a greater ICV value in the EF experiment as compared with the DS experiment $(p=0.036)$. In the same block, subjects tended to commit a greater number of commission errors in the EF experiment, although this effect did not reach statistical significance. No significant differences were observed for either the ICV or the number of commission errors during T6, corresponding to $24 \mathrm{~h}$ spent awake.

\section{Visuomotor test}

Changes in movement time relative to the baseline levels showed a similar course in the DS and EF experiments (Fig. 4c; Table 4). Specifically, we observed an initial decrease, with a nadir at T3, which was more pronounced and reached significance only during the DS experiment, suggesting a skill transfer from driving simulator practice to the motor task. After T3, movement time increased and reached a peak at T6. Importantly, while performance level did not significantly differ between the two experimental conditions either at T3 or T6, the DS experiment showed a stronger relative performance deficit at T6 when the block associated with the best performance (T3) was used as a reference (comparison of T3/T6 ratios, $p=0.03$, one tailed paired $t$ test). After recovery sleep, movement time showed a sharp decrease during both DS and EF experiments. Linear error, a measure of spatial accuracy, changed in the DS experiment, increasing from T3, reaching a peak at T6 and decreasing below baseline values after sleep (Fig. $4 d$; Table 4). No significant changes were noted for linear error during the EF experiment. Differences between the two experimental conditions were significant during block T6 $(p=0.03)$, but not during block T3.

\section{Spatial correlation between theta wave density at rest and behavioral performance}

We assessed the correlation between differences in performance and differences in theta wave density at rest during block T3 (12 h 
a Response Inhibition Test-Commission Errors
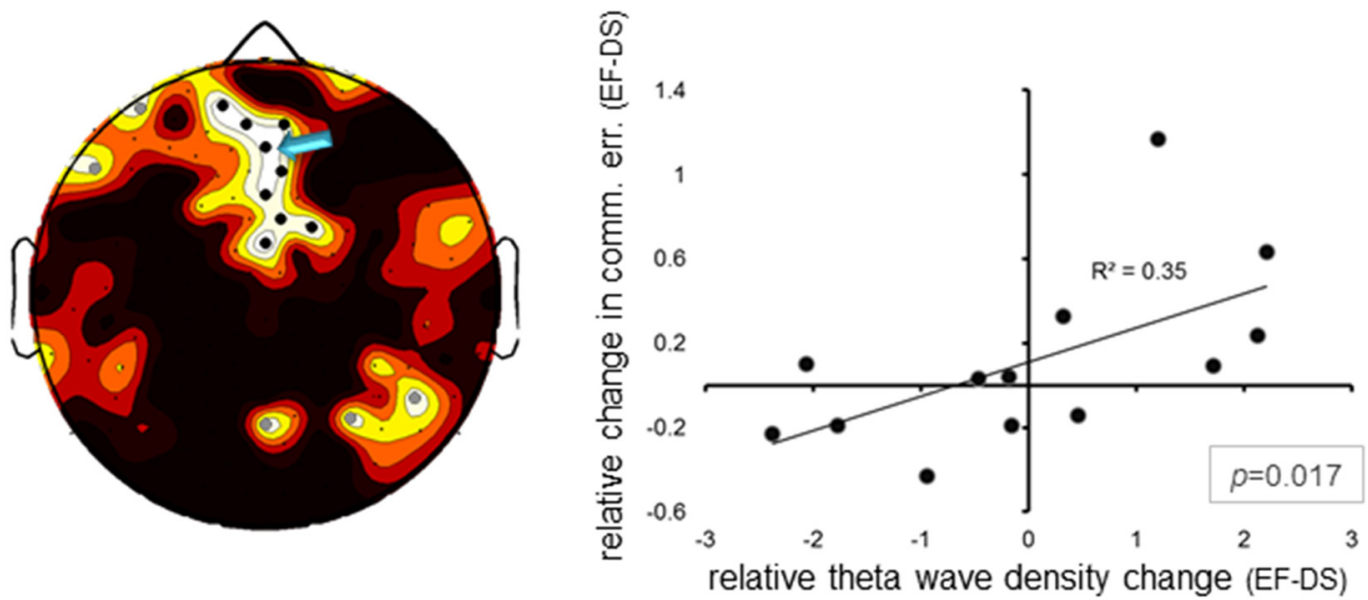

b Visuo-Motor Test-Movement Time
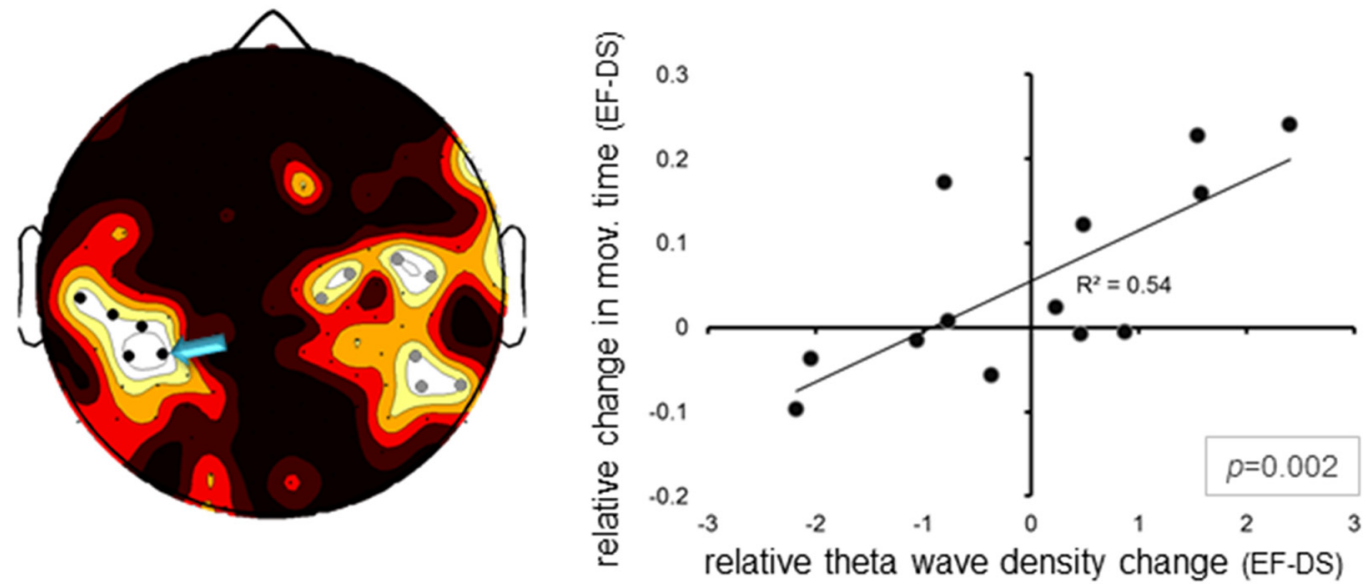

\section{c Visuo-Motor Test - Linear Error}

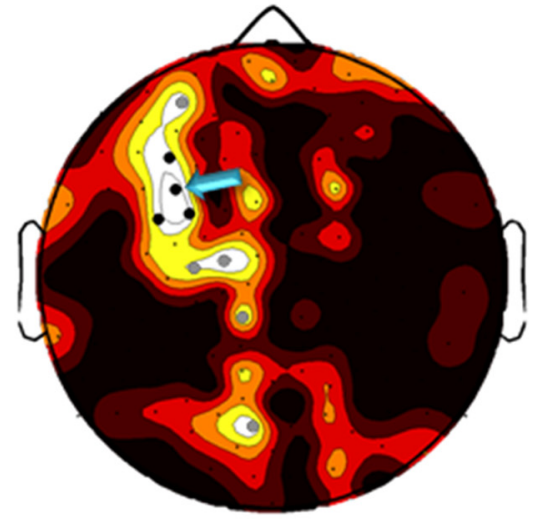

0
0.25

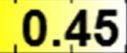

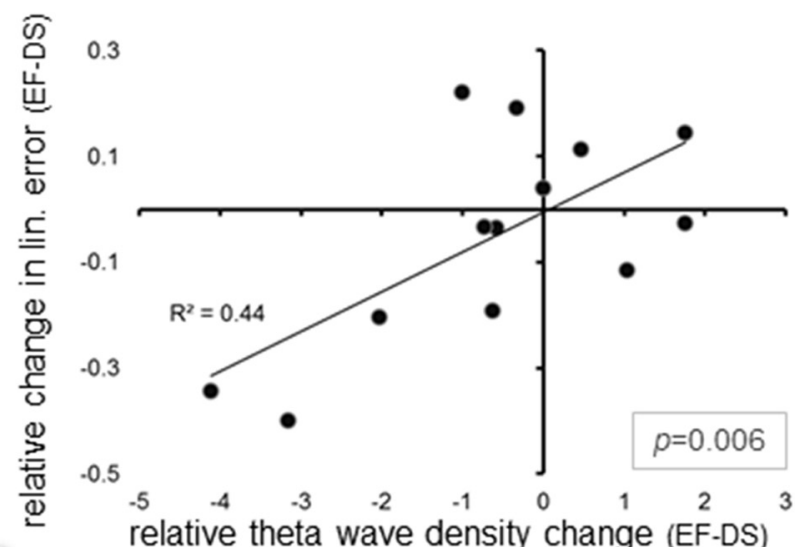

Correlation [r]

Figure 5. Correlation between changes in theta wave density and changes in behavioral performance during the two experimental conditions (DS, EF), for (a) commission errors during the response inhibition test, and $(\boldsymbol{b})$ movement time and (c) linear error, during the visuomotor test. The analysis focused on positive correlations (13 subjects), indicating a relationship between the relative difference in the local incidence of theta waves and the intrasubject relative changes in performance level associated with the two experiments. This analysis was performed on data collected during block T3 ( $\sim 12 \mathrm{~h}$ of waking). Black dots indicate significant correlations ( $p<0.05$, cluster size $>3$ electrodes), whereas gray dots are used to indicate below-threshold clusters. Scatter plots on the right display, for each of the three examined parameters, the relationship between theta activity and performance in a representative electrode indicated on the scalp plot by a light blue arrow. 
a

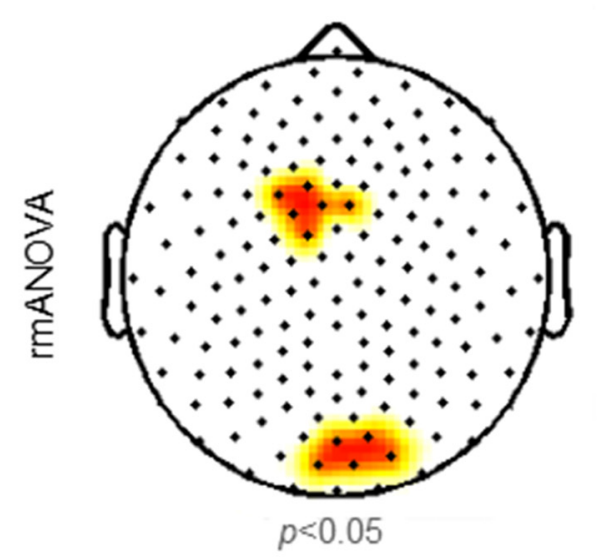

C $+0 /+500$ ms relative to stimulus onset

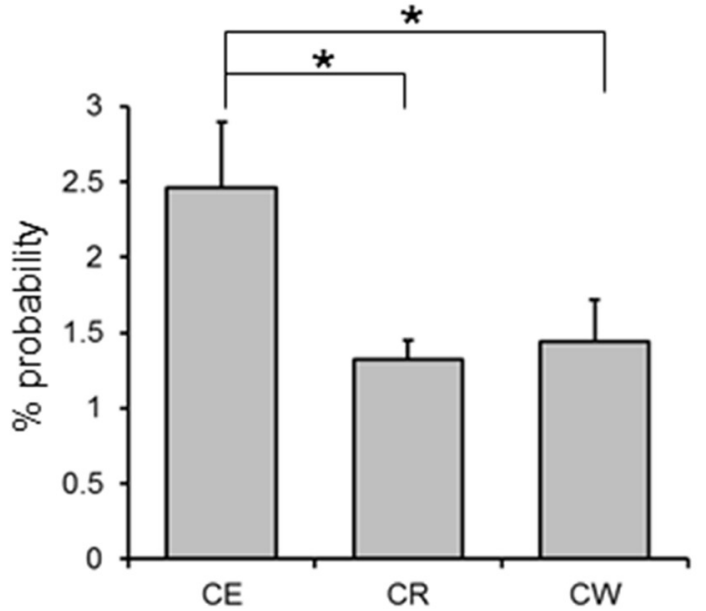

b

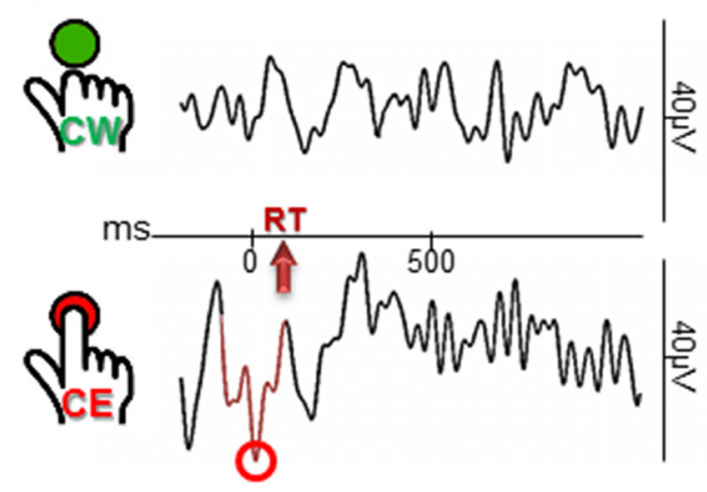

d $-150 /+150 \mathrm{~ms}$ relative to reaction time

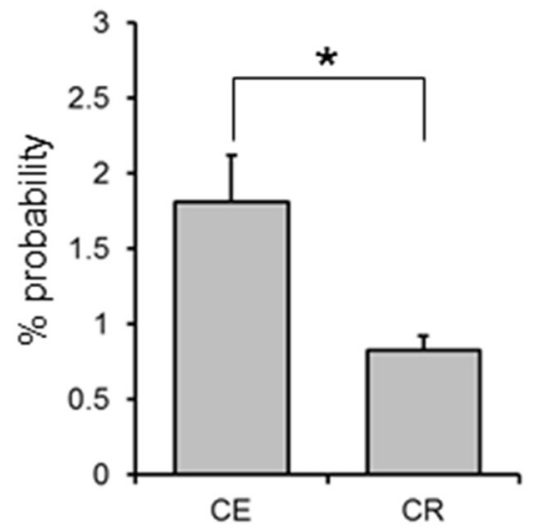

Figure 6. Association between theta waves and impulse control failures. The plot in $\boldsymbol{a}$ shows electrodes in which a significant outcome effect was detected using the two-way rmANOVA (13 subjects) including outcome (commission error, correct withhold) and experiment (DS and EF) as within-subjects factors ( $p<0.05$, cluster size $>3$ electrodes). $\boldsymbol{b}$, A representative example of EEG activity in a medial frontal electrode during correct withholds (top) and commission errors (bottom). Graphs in c and $\boldsymbol{d}$ show the mean probability of association of theta waves detected in frontal and posterior medial areas with the different outcomes (CE, commission error; CW, correct withhold; CR, correct response) in the 500 ms following stimulus presentation, and in a 300 ms time-window centered on the subjects' response, respectively ( \pm SE). For this latter case, when reaction time (RT) was shorter than $150 \mathrm{~ms}$, we used an asymmetric time-window that included the time between stimulus presentation and subject's response.

of wake). As detailed above, this time-point was selected primarily because confounding effects related to the generalized, aspecific increase in theta activity were minimal compared with subsequent recording sessions.

For the number of commission errors in the response inhibition test, we found a significant positive correlation with theta wave density (mean $r=0.59$, range $=0.48-0.67$ ) in channels located in medial frontal areas (Fig. $5 a$; similar results were obtained for ICV). Of note, a below-threshold cluster was also identified in the medial/right parietal region. Similar analyses performed for the visuomotor control function revealed a correlation between theta wave density at rest and movement time in electrodes located in left parieto-temporal areas (mean $r=0.64$, range $=0.53-0.74$; Fig. $5 b$ ), but below-threshold, symmetrical clusters were also present in the right hemisphere. Finally, a correlation between theta activity and linear error was observed in left frontal electrodes (mean $r=0.57$, range $=0.52-$ 0.67; Fig. $5 c$ ).

Importantly, we also determined whether a significant relationship existed between any of the tested behavioral parameters
(Pearson's coefficient, one-tailed test), as this would have implied a potential nonspecificity of the observed spatial correlations (i.e., the possibility for theta activity in one brain area to influence more than one behavioral parameter). We observed no significant positive correlations ( $p>0.51$ for all tests), with the exclusion of the one between commission errors and ICV $(r=0.74$, $p=0.002)$.

\section{Association between individual theta waves and impaired performance during test execution}

Response inhibition test

To verify whether individual theta waves could contribute to determine impulse control failures, for each electrode, we compared the probability of association between theta waves and commission errors, with the probability of having a theta wave in association with correct withholds during NoGo stimuli (testblock T3). The rmANOVA (outcome: commission error, correct withhold; experiment: EF, DS) revealed no significant experiment effect and no outcome X experiment interaction $(p<0.05)$. However, a significant outcome effect was observed in medial 
a

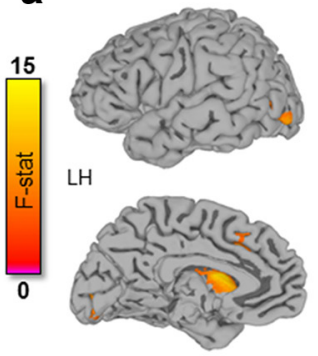

Mean Global Correlation

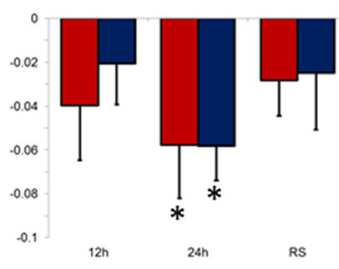

Signal Temporal Variability

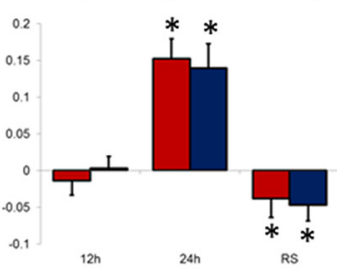

b

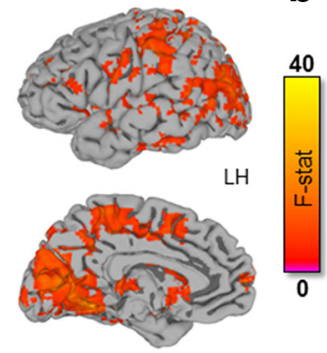

Driving Simulation $\square$ Executive Function

C
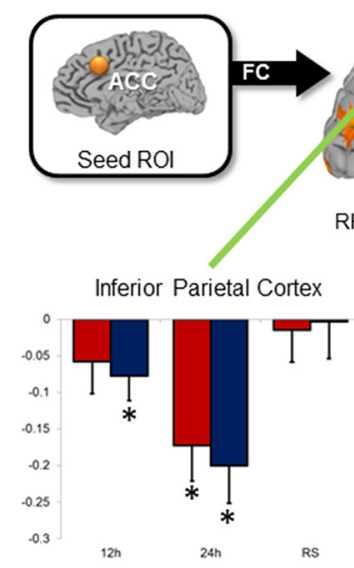

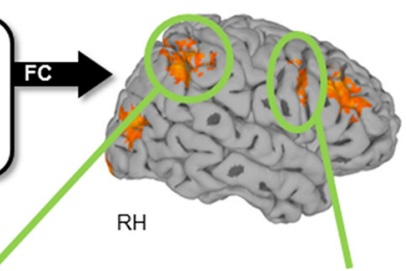

Middle/lnferior Frontal Cortex

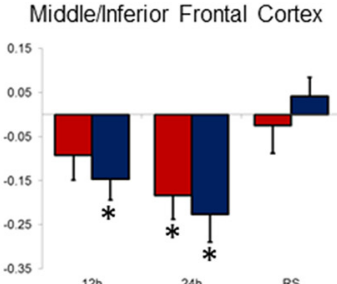

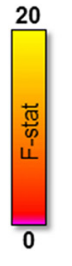

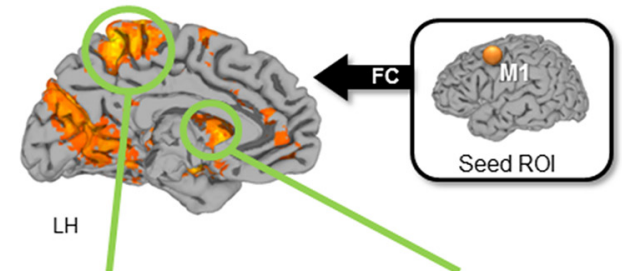

Medial/Superior Parietal Cortex

Caudate Nucleus (Bilateral)
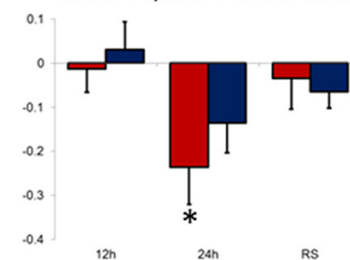
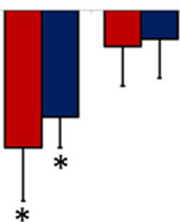

Figure 7. Effects of sleep deprivation on MRI-based measures of connectivity. $\boldsymbol{a}, \boldsymbol{b}$, Areas characterized by a significant modulation determined by prolonged wakefulness on mean global correlation (i.e., correlation of each voxel with all other brain voxels) and on temporal signal variability (i.e., mean square successive difference of the fMRI signal), respectively (14 subjects). The bar graphs show mean changes within significant voxels relative to the first MRI of the morning ( \pm SE). Moreover, for each subject and experiment, the Pearson's correlation coefficient was computed between the averaged signal time course of two seed R0ls known to be part of networks involved in impulse control (ACC; $\boldsymbol{c}$ ) and in visuomotor coordination (LM1; $\boldsymbol{d}$ ), and the time course of all the other voxels of the brain. Two-way rmANOVAs including experiment and scan session (BL, 12 h, $24 \mathrm{~h}$ ) were used to identify regions characterized by a significant connectivity modulation as a function of prior waking time. Within these areas, regions known to be relevant for impulse control and visuomotor control, respectively, were used to evaluate how connectivity changed across subsequent MRI sessions (bar graphs in bottom row).

frontal and medial posterior clusters (Fig. $6 a, b$ ). Direct comparisons within these areas confirmed that commission errors showed a higher probability of association with theta waves compared with correct withholds $(p=0.009)$, as well as correct responses $(p=0.018$; Fig. $6 c)$. No differences emerged between correct withholds and correct responses $(p=0.59)$. Additional analysis focused on a $300 \mathrm{~ms}$ time-window around the subjects' response (Fig. 6d) and confirmed a stronger probability of association between theta waves and the subject's motor responses during commission errors than during correct responses $(p=0.007)$.

\section{Visuomotor test}

An ROI-based approach was used to evaluate how the presence of theta waves in areas that showed a specific correlation between theta activity at rest and performance affected the subjects' visuomotor control during test execution (test-block T3). In both DS and EF experiments, we did not identify any significant increases in either movement time or linear error during movements in which theta waves were detected in the period between stimulus presentation and movement onset.

\section{Changes in MRI functional connectivity}

Resting fMRI time series collected every $12 \mathrm{~h}$ were analyzed to determine changes in both whole-brain and ROI-based connectivity during the two prolonged waking experiments. Specifically, we observed that mean global correlation and temporal signal variability were significantly modulated in a reciprocal manner during the two experiments. In fact, the strength of voxelwise mean whole-brain connectivity diffusely decreased, with a statistically significant bilateral effect in caudate nucleus, left middle occipital cortex, inferior occipital cortex and anterior cingulum (Fig. 7a). By contrast, signal temporal variability was characterized by a diffuse significant increase that prevalently involved occipital and parietal cortical areas (Fig. 7b). Both changes became significant after $24 \mathrm{~h}$ spent awake, and were reverted after $\sim 8$ h of sleep. No significant session $\mathrm{X}$ experiment interactions were observed. Of note, values of signal variability strongly decreased after recovery sleep, descending below baseline levels, perhaps in part due to interactions between homeostatic and circadian factors, as sleep was obtained during the day and the final data collection was performed in the afternoon.

In addition, we performed ROI-based analyses to evaluate potential changes in regional coupling within the functional networks of the anterior cingulate cortex (ACC-ROI) and of the left primary motor cortex (LM1-ROI) during DS and EF experiments. Specifically, we tested the hypothesis that the functional networks of these areas would be differently affected by the two experiments. Areas showing a significant $(p<0.05)$ difference between MRI sessions (BL, $12 \mathrm{~h}, 24 \mathrm{~h}$ ) for both the ACC- and the LM1-networks are shown in Table 5 (Fig. $7 c, d$ ). Correlation val- 


\begin{tabular}{|c|c|c|c|c|}
\hline Region & Hemisphere & $x$ & $Y$ & $Z$ \\
\hline \multicolumn{5}{|l|}{ EF experiment ( $\mathrm{ACC}$ ROI) } \\
\hline \multirow[t]{2}{*}{ Middle occipital gyrus } & Left & -31 & -69 & 4 \\
\hline & Right & 29 & -69 & 22 \\
\hline \multirow[t]{3}{*}{ Middle frontal gyrus } & Left & -31 & 21 & 26 \\
\hline & Right & 39 & 29 & 30 \\
\hline & Left & -51 & -47 & 38 \\
\hline \multirow[t]{2}{*}{ Precentral gyrus } & Left & -33 & 1 & 34 \\
\hline & Right & 45 & 6 & 33 \\
\hline Inferior parietal lobule & Right & 51 & -49 & 48 \\
\hline \multirow[t]{2}{*}{ Lingual gyrus } & Left & -25 & -89 & -16 \\
\hline & Right & 25 & -97 & -12 \\
\hline \multirow[t]{2}{*}{ Caudate nucleus } & Left & -11 & 7 & 12 \\
\hline & Right & 11 & 3 & 18 \\
\hline Thalamus & Right & 15 & -29 & 4 \\
\hline \multicolumn{5}{|l|}{ DS experiment (LM1 ROI) } \\
\hline \multirow{2}{*}{ Superior temporal gyrus } & Left & -63 & -11 & 4 \\
\hline & Right & 65 & -9 & 2 \\
\hline Precuneus & Left & -9 & -49 & 60 \\
\hline Parahippocampal gyrus & Right & 23 & 1 & -10 \\
\hline Middle temporal gyrus & Left & -45 & -73 & 22 \\
\hline Superior frontal gyrus & Left & -11 & 57 & -8 \\
\hline Medial frontal gyrus & Left & -3 & 1 & 60 \\
\hline Caudate nucleus & Right & 11 & 13 & 18 \\
\hline Lentiform nucleus & Left & -25 & 5 & 8 \\
\hline
\end{tabular}

ues within the ACC-network were significantly reduced after $12 \mathrm{~h}$ of wake relative to baseline levels, during both DS $(p=0.03)$ and $\mathrm{EF}(p=0.002)$ experiments, and a further reduction was observed at $24 \mathrm{~h}$. By contrast, within the LM1-network, functional connectivity tended to remain stable after $12 \mathrm{~h}$, and a significant reduction appeared only after 24 h of waking in both DS ( $p=$ $0.01)$ and EF $(p=0.004)$. For both the examined networks, recovery sleep was associated with the return of functional connectivity to baseline levels.

Importantly, no significant interaction effects emerged in the two rmANOVAs evaluating the task-related networks. However, we observed that connectivity of ACC with two key regions of the impulse control network, i.e., right IPL and right inferior frontal gyrus (Garavan et al., 2002), was significantly decreased after $12 \mathrm{~h}$ spent awake in the EF, but not in the DS condition (Fig. 7c). Similarly, connectivity of LM1 with the medial/superior parietal cortex decreased significantly after $24 \mathrm{~h}$ in the DS but not in the EF experiment (Fig. 7c). By contrast, connectivity of LM1 with the striatum showed a significant decrease at both 12 and $24 \mathrm{~h}$ of wake in both experimental conditions (Fig. $7 d$ ).

\section{Discussion}

In rats, the local occurrence of neuronal OFF periods has been linked directly to performance errors during extended wake (Vyazovskiy et al., 2011), but evidence supporting a similar relationship in humans was still lacking. Here we show, for the first time, that extended practice with tasks relying on EFs leads to less efficient impulse control, whereas practice with a DS results in relative impairment in visuomotor control. We also found a specific spatial correlation between theta wave density at rest and relative changes in performance, as well as a specific temporal association between individual theta waves and changes in performance during test execution. Finally, an fMRI-based connectivity analysis indicates that performance impairment may depend both on a local and on long-range effects caused by a breakdown in connectivity.

\section{Prolonged wakefulness is associated with a homeostatic global increase in sleep pressure}

As expected, prolonged wakefulness was associated with changes in parameters indicating a generalized increase in sleep pressure. Specifically, self-reported variations in alertness/sleepiness were similar in the two experimental conditions and revealed an initial increase in sleep pressure after $\sim 8 \mathrm{~h}$ spent awake, followed by a temporary reduction or stabilization, and by a new steep increase after $\sim 16 \mathrm{~h}$ of wakefulness. The reaction time in the PVT followed a similar time course, confirming the strong correlation between subjective scales and this objective measure of sleepiness (Hung et al., 2013). Moreover, these changes were paralleled by global changes in EEG theta power, in-line with evidence pointing at theta/alpha activity as a marker of sleep need in humans (Finelli et al., 2000). Finally, all measures of sleepiness renormalized after $\sim 8 \mathrm{~h}$ of sleep. Importantly, no significant differences were observed between the two experimental conditions, suggesting that they were characterized by similar global homeostatic changes in sleep need and that local, experience-dependent use did not influence subjective sleepiness or the general vigilance level.

\section{Theta activity in task-related areas is associated with impaired behavioral performance}

Our results showed that when subjects practiced with tasks relying on self-control for a prolonged time (EF), their ability to efficiently control impulses was more negatively affected than when they were involved in a task based on visuomotor coordination (DS). Conversely, prolonged practice with this latter task was associated with a decrease in visuomotor accuracy and with a relative increase in movement time that became evident after $\sim 17 \mathrm{~h}$ spent awake. In fact, although the maximal movement time, reached at the end of the $24 \mathrm{~h}$, was similar in the two experiments, the DS experiment was associated with a stronger decrease in movement time during the first $\sim 12 \mathrm{~h}$. We hypothesize that practice with the driving simulator may have granted an initial benefit to visuomotor performance, with a relative increase in movement speed at the expenditure of a relatively small decrease in accuracy. However, these initial changes may have led to a faster consumption of task-related functional resources and to a consequent progressive reduction in visuomotor coordination efficiency, which determined a rapid increase in linear error not compensated by the parallel increase in movement time (as conversely observed in EF).

Although the impairment in visuomotor control became evident only toward the end of the sleep deprivation, differences in impulse control efficiency increased during the first $12 \mathrm{~h}$ spent awake and decreased afterward, suggesting that distinct brain networks may have different vulnerability to cognitive overload. Of note, a recruitment of prefrontal areas, involved in many cognitive functions (Niendam et al., 2012), was inevitable during DS and, in general, during sleep deprivation, which can be regarded as a self-control task per se. The consequent functional overlap, together with the global theta power increase that started after $16 \mathrm{~h}$ of wake, may have led to a ceiling effect that masked potential behavioral differences between the two experiments.

Importantly, we observed a correlation between theta wave density at rest and measures indicating a reduced efficiency in impulse control in electrodes located in medial frontal areas. This finding is consistent with evidence indicating a key role of the MPFC/ACC, together with the inferior frontal gyrus and the IPL, in response inhibition (Swick et al., 2011) and control of aggressive behavior (Pietrini et al., 2000). Similarly, a specific correla- 
tion between movement time in the visuomotor test and theta activity at rest was observed in parieto-temporal areas, potentially related to coordination of vision-guided arm movements (Culham et al., 2006). In addition, we observed a correlation between theta activity and linear error in left frontal electrodes, potentially corresponding to motor and premotor areas. Indeed, an increased incidence of OFF periods in these regions could have been responsible for a difficulty in producing correct movements, with a consequent increased need for on-line adjustments and/or reduced accuracy.

\section{Theta waves are temporally associated with performance errors}

To explore further the correlation between local sleep and behavior, we tested the hypothesis that individual theta waves occurring with a specific regional involvement and temporal association to the stimulus could contribute to alter performance. Specifically, we demonstrated that during both DS and EF experiments, theta waves occurring in medial frontal and medial posterior electrodes had a significantly higher probability to be associated with impulse control failures than with correct withholds during NoGo trials, as well as correct responses during Go stimuli. Importantly, these electrodes were located within regions for which an association between theta activity at rest and a relative impairment in the impulse control function was observed. Thus, theta waves occurring in occipitoparietal areas could be responsible for an altered low-level processing and "labeling" of the stimulus (Menon et al., 2001). On the other hand, the medial frontal cluster is compatible with an origin of the theta waves in the MPFC/ACC, which is known to be involved in detection of response conflicts and in errors processing (Garavan et al., 2002). Hypoactivity of the MPFC/ACC during response inhibition has been observed in individuals with difficulties in maintaining attention, suggesting that a disrupted activity of this region could determine impulse control failures by compromising top-down control (Hester et al., 2004).

We found no temporal association between theta waves and increases in movement time or linear error. However, various factors could explain these negative results, including the observation that motor control optimization was apparently still ongoing during the evaluated time-point, and the possible lower vulnerability of visuomotor coordination to the effects of local sleep. Therefore, future studies will be necessary to better characterize the association between theta waves and performance changes during visuomotor tasks.

\section{Prolonged wakefulness leads to a breakdown in functional connectivity}

During sleep, EEG slow-waves and the underlying neuronal OFF periods are associated with a breakdown in effective connectivity (Massimini et al., 2005). Thus, if theta waves occurring in wake represent the signature of OFF periods functionally similar to those observed in sleep, their increase should be accompanied by a reduction in inter-regional connectivity. In line with this hypothesis, our results indicate that prolonged wakefulness is associated with a decrease in measures representing the mean strength of coupling among brain areas. Interestingly, this reduction was especially pronounced bilaterally in the caudate nucleus, a structure involved in the regulation of the sleep-wake cycle (Villablanca et al., 1976). Similarly, decreases in connectivity were observed within the networks of anterior cingulate cortex and left primary motor cortex, respectively related to impulse control and motor control (Guye et al., 2003; Garavan et al.,
2006). Moreover, our results showed that prolonged wakefulness leads to a global increase in signal variability, a measure recently proposed to be related to connectivity and information integration (Garrett et al., 2011). Nonetheless, evidence suggests that an excessive increase in variability may indicate a decreased signalto-noise ratio, with a negative impact on functional efficiency (Samanez-Larkin et al., 2010). Thus, consistent with previous research (De Havas et al., 2012), present results demonstrate that the homeostatic increase in theta activity is paralleled by a "network disintegration."

Our results also revealed that changes involving task-related networks paralleled changes in behavioral performance. In fact, a decrease in connectivity between anterior cingulate cortex and key regions of the impulse control network reached significance already after $12 \mathrm{~h}$ of practice with the EF tasks, but not after practice with the driving simulator. On the other hand, the DS experiment (but not EF) was associated with a significant reduction in functional coupling between left primary motor cortex and the superior/medial parietal cortex. Thus, although additional studies on larger samples will be required to obtain conclusive evidence, present results suggest that together with a general, aspecific decrease in connectivity, a smaller, local effect related to a "network-specific overload" may also exist.

\section{Conclusions}

The described results indicate that temporary deactivations of brain areas involved in specific activities can potentially determine relevant behavioral alterations, and suggest that different brain areas or functional networks could be characterized by different degrees of vulnerability to cognitive fatigue. Importantly, these findings may contribute explaining the commonly observed relationship between sleep deprivation/restriction and behavioral impulsiveness or disinhibition, which, in the most extreme cases, may even determine explosive aggressive behaviors.

\section{References}

Alhola P, Polo-Kantola P (2007) Sleep deprivation: impact on cognitive performance. Neuropsychiatr Dis Treat 3:553-567. Medline

Basner M, Dinges D (2011) Maximizing sensitivity of the psychomotor vigilance test (PVT) to sleep loss. Sleep 34:581-591. Medline

Baumeister RF, Bratslavsky E, Muraven M, Tice DM (1998) Ego depletion: is the active self a limited resource? J Pers Soc Psychol 74:1252-1265. CrossRef Medline

Bernardi G, Ricciardi E, Sani L, Gaglianese A, Papasogli A, Ceccarelli R, Franzoni F, Galetta F, Santoro G, Goebel R, Pietrini P (2013) How skill expertise shapes the brain functional architecture: an fMRI study of visuo-spatial and motor processing in professional racing-car and naïve drivers. PLoS One 8:e77764. CrossRef Medline

Bernardi G, Cecchetti L, Handjaras G, Sani L, Gaglianese A, Ceccarelli R, Franzoni F, Galetta F, Santoro G, Goebel R, Ricciardi E, Pietrini P (2014) It's not all in your car: functional and structural correlates of exceptional driving skills in professional racers. Front Hum Neurosci 8:888. CrossRef Medline

Chuah YM, Venkatraman V, Dinges DF, Chee MW (2006) The neural basis of interindividual variability in inhibitory efficiency after sleep deprivation. J Neurosci 26:7156-7162. CrossRef Medline

Cirelli C, Tononi G (2008) Is sleep essential? PLoS Biol 6:e216. CrossRef Medline

Cox RW (1996) AFNI: software for analysis and visualization of functional magnetic resonance neuroimages. Comput Biomed Res 29:162-173. CrossRef Medline

Cox RW (2012) AFNI: what a long strange trip it's been. Neuroimage 62: 743-747. CrossRef Medline

Culham JC, Cavina-Pratesi C, Singhal A (2006) The role of parietal cortex in visuomotor control: what have we learned from neuroimaging? Neuropsychologia 44:2668-2684. CrossRef Medline

De Havas JA, Parimal S, Soon CS, Chee MW (2012) Sleep deprivation re- 
duces default mode network connectivity and anti-correlation during rest and task performance. Neuroimage 59:1745-1751. CrossRef Medline

Delorme A, Makeig S (2004) EEGLAB: an open source toolbox for analysis of single-trial EEG dynamics including independent component analysis. J Neurosci Methods 134:9-21. CrossRef Medline

DeWall CN, Baumeister RF, Stillman TF, Gailliot MT (2007) Violence restrained: effects of self-regulation and its depletion on aggression. J Exp Soc Psychol 43:62-76. CrossRef

Dinges DF, Powell JW (1985) Microcomputer analyses of performance on a portable, simple visual RT task during sustained operations. Behav Res Methods Instr Comp 17:652-655.

Eickhoff SB, Stephan KE, Mohlberg H, Grefkes C, Fink GR, Amunts K, Zilles K (2005) A new SPM toolbox for combining probabilistic cytoarchitectonic maps and functional imaging data. Neuroimage 25:1325-1335. CrossRef Medline

Finelli LA, Baumann H, Borbély AA, Achermann P (2000) Dual electroencephalogram markers of human sleep homeostasis: correlation between theta activity in waking and slow-wave activity in sleep. Neuroscience 101:523-529. CrossRef Medline

Fischer P, Greitemeyer T, Frey D (2008) Self-regulation and selective exposure: the impact of depleted self-regulation resources on confirmatory information processing. J Pers Soc Psychol 94:382-395. CrossRef Medline

Forman SD, Cohen JD, Fitzgerald M, Eddy WF, Mintun MA, Noll DC (1995) Improved assessment of significant activation in functional magnetic resonance imaging (fMRI): use of a cluster-size threshold. Magn Reson Med 33:636-647. CrossRef

Gailliot MT, Baumeister RF, DeWall CN, Maner JK, Plant EA, Tice DM, Brewer LE, Schmeichel BJ (2007) Self-control relies on glucose as a limited energy source: willpower is more than a metaphor. J Pers Soc Psychol 92:325-336. CrossRef Medline

Garavan H, Ross TJ, Stein EA (1999) Right hemispheric dominance of inhibitory control: an event-related functional MRI study. Proc Natl Acad Sci U S A 96:8301-8306. CrossRef Medline

Garavan H, Ross TJ, Murphy K, Roche RA, Stein EA (2002) Dissociable executive functions in the dynamic control of behavior: inhibition, error detection, and correction. Neuroimage 17:1820-1829. CrossRef Medline

Garavan H, Hester R, Murphy K, Fassbender C, Kelly C (2006) Individual differences in the functional neuroanatomy of inhibitory control. Brain Res 1105:130-142. CrossRef Medline

Garrett DD, Kovacevic N, McIntosh AR, Grady CL (2010) Blood oxygen level-dependent signal variability is more than just noise. J Neurosci 30: 4914-4921. CrossRef Medline

Garrett DD, Kovacevic N, McIntosh AR, Grady CL (2011) The importance of being variable. J Neurosci 31:4496-4503. CrossRef Medline

Ghilardi MF, Eidelberg D, Silvestri G, Ghez C (2003) The differential effect of PD and normal aging on early explicit sequence learning. Neurology 60:1313-1319. CrossRef Medline

Ghilardi MF, Moisello C, Silvestri G, Ghez C, Krakauer JW (2009) Learning of a sequential motor skill comprises explicit and implicit components that consolidate differently. J Neurophysiol 101:2218-2229. CrossRef Medline

Guye M, Parker GJ, Symms M, Boulby P, Wheeler-Kingshott CA, SalekHaddadi A, Barker GJ, Duncan JS (2003) Combined functional MRI and tractography to demonstrate the connectivity of the human primary motor cortex in vivo. Neuroimage 19:1349-1360. CrossRef Medline

Hester R, Fassbender C, Garavan H (2004) Individual differences in error processing: a review and reanalysis of three event-related fMRI studies using the GO/NOGO task. Cereb Cortex 14:986-994. CrossRef Medline

Hewig J, Trippe R, Hecht H, Coles MG, Holroyd CB, Miltner WH (2007) Decision-making in blackjack: an electrophysiological analysis. Cereb Cortex 17:865-877. CrossRef Medline

Hewig J, Straube T, Trippe RH, Kretschmer N, Hecht H, Coles MG, Miltner WH (2009) Decision-making under risk: an fMRI study. J Cogn Neurosci 21:1642-1652. CrossRef Medline

Hofmann W, Schmeichel BJ, Baddeley AD (2012) Executive functions and self-regulation. Trends Cogn Sci 16:174-180. CrossRef Medline

Hung CS, Sarasso S, Ferrarelli F, Riedner B, Ghilardi MF, Cirelli C, Tononi G (2013) Local experience-dependent changes in the wake EEG after prolonged wakefulness. Sleep 36:59-72. CrossRef Medline

Jeong M, Tashiro M, Singh LN, Yamaguchi K, Horikawa E, Miyake M, Watanuki S, Iwata R, Fukuda H, Takahashi Y, Itoh M (2006) Functional brain mapping of actual car-driving using [18F]FDG-PET. Ann Nucl Med 20:623-628. CrossRef Medline

Jewett ME, Wyatt JK, Ritz-De Cecco A, Khalsa SB, Dijk DJ, Czeisler CA (1999) Time course of sleep inertia dissipation in human performance and alertness. J Sleep Res 8:1-8. CrossRef Medline

Kamphuis J, Meerlo P, Koolhaas JM, Lancel M (2012) Poor sleep as a potential causal factor in aggression and violence. Sleep Med 13:327-334. CrossRef Medline

Lavie P (1986) Ultrashort sleep-waking schedule. III."Gates" and "forbidden zones” for sleep. Electroencephalogr Clin Neurophysiol 63:414-425. CrossRef Medline

Leo A, Bernardi G, Handjaras G, Bonino D, Ricciardi E, Pietrini P (2012) Increased BOLD variability in the parietal cortex and enhanced parietooccipital connectivity during tactile perception in congenitally blind individuals. Neural Plast 2012:720278. CrossRef Medline

Lund TE, Madsen KH, Sidaros K, Luo WL, Nichols TE (2006) Non-white noise in fMRI: does modelling have an impact? Neuroimage 29:54-66. CrossRef Medline

Massimini M, Ferrarelli F, Huber R, Esser SK, Singh H, Tononi G (2005) Breakdown of cortical effective connectivity during sleep. Science 309: 2228-2232. CrossRef Medline

Menon V, Adleman NE, White CD, Glover GH, Reiss AL (2001) Errorrelated brain activation during a Go/NoGo response inhibition task. Hum Brain Mapp 12:131-143. CrossRef Medline

Moisello C, Bove M, Huber R, Abbruzzese G, Battaglia F, Tononi G, Ghilardi MF (2008) Short-term limb immobilization affects motor performance. J Mot Behav 40:165-176. CrossRef Medline

Moisello C, Perfetti B, Marinelli L, Sanguineti V, Bove M, Feigin A, Di Rocco A, Eidelberg D, Ghilardi MF (2011) Basal ganglia and kinematics modulation: insights from Parkinson's and Huntington's diseases. Parkinson Relat Disor 17:642-644. CrossRef

Mueller ST (2009) PEBL: the psychology experiment building language (version 0.10) [Computer experiment programming language]. Accessed November 2009. http://pebl.sourceforge.net.

Muraven M, Slessareva E (2003) Mechanisms of self-control failure: motivation and limited resources. Pers Soc Psychol Bull 29:894-906. CrossRef Medline

Muraven M, Tice DM, Baumeister RF (1998) Self-control as limited resource: regulatory depletion patterns. J Pers Soc Psychol 74:774-789. CrossRef Medline

Niendam TA, Laird AR, Ray KL, Dean YM, Glahn DC, Carter CS (2012) Meta-analytic evidence for a superordinate cognitive control network subserving diverse executive functions. Cogn Affect Behav Neurosci 12: 241-268. CrossRef Medline

Nobili L, Ferrara M, Moroni F, De Gennaro L, Russo GL, Campus C, Cardinale F, De Carli F (2011) Dissociated wake-like and sleep-like electrocortical activity during sleep. Neuroimage 58:612-619. CrossRef Medline

Nuñez JM, Casey BJ, Egner T, Hare T, Hirsch J (2005) Intentional false responding shares neural substrates with response conflict and cognitive control. Neuroimage 25:267-277. CrossRef Medline

Pietrini P, Guazzelli M, Basso G, Jaffe K, Grafman J (2000) Neural correlates of imaginal aggressive behavior assessed by positron emission tomography in healthy subjects. Am J Psychiatry 157:1772-1781. CrossRef Medline

Rector DM, Topchiy IA, Carter KM, Rojas MJ (2005) Local functional state differences between rat cortical columns. Brain Res 1047:45-55. CrossRef Medline

Ricciardi E, Handjaras G, Bernardi G, Pietrini P, Furey ML (2013) Cholinergic enhancement reduces functional connectivity and BOLD variability in visual extrastriate cortex during selective attention. Neuropharmacology 64:305-313. CrossRef Medline

Riedner BA, Vyazovskiy VV, Huber R, Massimini M, Esser S, Murphy M, Tononi G (2007) Sleep homeostasis and cortical synchronization: III. A high-density EEG study of sleep slow waves in humans. Sleep 30:16431657. Medline

Roach GD, Dawson D, Lamond N (2006) Can a shorter psychomotor vigilance task be used as a reasonable substitute for the ten-minute psychomotor vigilance task? Chronobiol Int 23:1379-1387. CrossRef Medline

Roche RA, Garavan H, Foxe JJ, O’Mara SM (2005) Individual differences discriminate event-related potentials but not performance during response inhibition. Exp Brain Res 160:60-70. CrossRef Medline 
Samanez-Larkin GR, Kuhnen CM, Yoo DJ, Knutson B (2010) Variability in nucleus accumbens activity mediates age-related suboptimal financial risk taking. J Neurosci 30:1426-1434. CrossRef Medline

Siclari F, Bernardi G, Riedner BA, LaRocque JJ, Benca RM, Tononi G (2014) Two distinct synchronization processes in the transition to sleep: a highdensity electroencephalographic study. Sleep 37:1621-1637. CrossRef Medline

Stroop JR (1992) Studies of interference in serial verbal reactions [reprinted from J Exp Psychol 18:643-662 (1935)]. J Exp Psychol Gen 121:15-23. CrossRef

Stucke TS, Baumeister RF (2006) Ego depletion and aggressive behavior: is the inhibition of aggression a limited resource? Eur J Soc Psychol 36:1-13. CrossRef

Stuss DT, Murphy KJ, Binns MA, Alexander MP (2003) Staying on the job: the frontal lobes control individual performance variability. Brain 126: 2363-2380. CrossRef Medline

Swick D, Ashley V, Turken U (2011) Are the neural correlates of stopping and not going identical? Quantitative meta-analysis of two response inhibition tasks. Neuroimage 56:1655-1665. CrossRef Medline

Talairach J, Tournoux P (1988) Co-planar stereotaxic atlas of the human brain. New York: Thieme Medical.
Tomasi D, Volkow ND (2010) Functional connectivity density mapping. Proc Natl Acad Sci U S A 107:9885-9890. CrossRef Medline

Villablanca JR, Marcus RJ, Olmstead CE (1976) Effects of caudate nuclei or frontal cortex ablations in cats: II. Sleep-wakefulness, EEG, and motor activity. Exp Neurol 53:31-50. CrossRef Medline

Vohs KD, Heatherton TF (2000) Self-regulatory failure: a resourcedepletion approach. Psychol Sci 11:249-254. CrossRef Medline

Vohs KD, Baumeister RF, Schmeichel BJ, Twenge JM, Nelson NM, Tice DM (2008) Making choices impairs subsequent self-control: a limitedresource account of decision making, self-regulation, and active initiative. J Pers Soc Psychol 94:883-898. CrossRef Medline

von Neumann J, Kent RH, Bellinson HR, Hart BI (1941) The mean square successive difference. Ann Math Stat 12:153-162. CrossRef

Vyazovskiy VV, Olcese U, Hanlon EC, Nir Y, Cirelli C, Tononi G (2011) Local sleep in awake rats. Nature 472:443-447. CrossRef Medline

Walter H, Vetter SC, Grothe J, Wunderlich AP, Hahn S, Spitzer M (2001) The neural correlates of driving. Neuroreport 12:1763-1767. CrossRef Medline

Zar JH (1996) Biostatistical analysis, Ed 3. Upper Saddle River, New Jersey: Prentice Hall. 